\title{
An $S d u I$ polymorphism at intron 20 of the Chinese Holstein cow STAT4 gene and its effect on milk performance traits
}

\author{
X.M. Song ${ }^{1 *}$, L. Zhang ${ }^{1,2 *}$, J.F. Jiang ${ }^{1}$, F.X. Shi ${ }^{2}$ and Y.Q. Jiang ${ }^{1}$ \\ ${ }^{1}$ Institute of Animal Husbandry and Veterinary Science, \\ Zhejiang Academy of Agricultural Sciences, Hangzhou, China \\ ${ }^{2}$ College of Animal Science and Technology, Nanjing Agricultural University, \\ Nanjing, China \\ *These authors contributed equally to this study. \\ Corresponding authors: X.M. Song / Y.Q. Jiang \\ E-mail: songxuemei@yeah.net /.jyq61@sohu.com
}

Genet. Mol. Res. 12 (2): 1593-1602 (2013)

Received September 26, 2012

Accepted January 3, 2013

Published May 13, 2013

DOI http://dx.doi.org/10.4238/2013.May.13.13

\begin{abstract}
The signal transducer and activator of transcription (STAT) genes are responsive to a wide range of cytokines, growth factors, and hormones, and thus control important biological processes. In humans, STAT4 mutations have been identified as genetic markers for rheumatoid arthritis, systemic lupus erythematosus, and primary Sjögren's syndrome, whereas little research has been conducted on bovine STAT4 mutations and their potential effects. Herein, 585 Chinese Holstein cows were used to investigate STAT4 mutations and their effects on milk performance traits. One haplotype block, containing g.95879G $>$ A, g.96013G $>$ C, was identified in intron 20 of the bovine STAT4 gene by restriction fragment length polymorphism-polymerase chain reaction and DNA sequencing. Two single nucleotide polymorphisms were significantly associated with milk yield at 305 days $(\mathrm{P}<0.05)$, and with protein percentage $(\mathrm{P}<0.05)$. Chinese Holstein cows with the haplotype GGGG had higher milk yields at 305 days and lower protein percentages. These results suggest that the 2
\end{abstract}


single nucleotide polymorphisms of STAT4 could be used as genetic markers for milk performance traits in Chinese Holstein cows.

Key words: STAT4; Polymorphism; Milk performance traits; Chinese Holstein cow

\section{INTRODUCTION}

The Janus kinase/signal transducer and activator of transcription (STAT) pathways, first identified in interferon systems, are responsive to a wide range of cytokines, growth factors, and hormones, and thus control important biological processes, including cell growth, cell differentiation, apoptosis, and immune responses (Levy and Darnell, 2002). In mammals, 7 distinct STAT genes (STAT1, STAT2, STAT3, STAT4, STAT5A, STAT5B, and STAT6) have been identified in the STAT family (Darnell, 1997). During a mammary developmental cycle, STATs are activated sequentially in the order STAT1-STAT4-STAT6-STAT5-STAT3-STAT1, to orchestrate the processes of functional differentiation, cell death, and tissue remodeling (Watson and Neoh, 2008).

Many studies have revealed that each STAT shows specific roles in the adult mammary developmental cycle. STAT1, STAT3, and STAT5 are activated in response to prolactin and form homo- and heterodimers that bind to $\gamma$-interferon-activated sequence elements in the promoters of prolactin-induced expression of both milk proteins and interferon-regulatory factor-1 genes (Schmitt-Ney et al., 1992; Sims et al., 1993; Gouilleux et al., 1994). Moreover, STAT5 plays a critical role in regulating the maximal expression of milk protein genes (Burdon et al., 1994; Gouilleux et al., 1994; Wakao et al., 1995; Yamaji et al., 2009).

STAT4 is also known to play an important role in the mammary gland (Watson and Neoh, 2008). STAT4 expression is relatively restricted; it has high expression in the testis, lymphoid, myeloid tissue, non-epithelial cells, or a subset of undifferentiated epithelial cells, and its expression is severely diminished in mammary epithelial cells (Zhong et al., 1994; Horvath, 2000). Moreover, STAT4 is expressed in a reciprocal manner to STAT5, becoming undetectable by day 10 of gestation (Philp et al., 1996). These observations suggest that STAT4 needs to be suppressed to allow for STAT6 activity that is required for lineage commitment and STAT5 activity (Khaled et al., 2007).

Among the members of the STAT family, STAT5A has been recently studied as a candidate gene for 5 milk production traits (milk yield at 305 days, protein percentage, fat percentage, lactose percentage, and dry matter percentage). Polymorphisms in cattle STAT5A and their associations with milk performance traits were investigated in Holstein cows (Brym et al., 2004; Khatib et al., 2008; He et al., 2012), Jersey cows (Dario and Selvaggi, 2011), and Italian Brown cattle (Flisikowski et al., 2003; Selvaggi et al., 2009). Many STAT5A polymorphisms appear to be a promising indirect marker to improve milk production traits in cattle. To date, few polymorphisms within the bovine STAT4 gene have been reported. A recent study demonstrated the contribution of bovine STAT4 polymorphisms to milk production traits, which indicated the potential link between STAT4 mutations and milk production traits (Zhang et al., 2010). Here, we found 2 novel polymorphisms from intron 20 of STAT4 in Chinese Holstein cows, and showed their significance for milk performance traits. These results supported the hypothesis that the 2 single nucleotide polymorphisms (SNPs) in intron 20 of STAT4 could be used as genetic markers for milk performance traits in Chinese Holstein cows. 


\section{MATERIAL AND METHODS}

\section{Experimental animals}

Genomic DNA from 585 randomly chosen Chinese Holstein cows was used to determine the allele frequencies of the STAT4 sequence polymorphisms and their associations with milk performance traits in the first 3 lactations. Data of milk performance traits [milk yield at 305 days $(\mathrm{kg})$, fat percentage, and protein percentage] were collected from the laboratory of dairy herd improvement. Cows used in the experiment came from the same Qingdao commercial farm in the Shandong Province (China) to minimize potential environmental factors that could interfere with the effects of SNPs. Because the milk records were collected during a complete 305-day lactation, the effect of season was also minimized. The effect of origin (especially the effect of the sire) could also be ignored since the cows were the daughters of many different sires that were randomly distributed in the SNP genotype cow groups.

\section{Primers, PCR amplification, genotyping, sequencing, and analysis of mutations}

One pair of primers was designed according to the bovine STAT4 sequence (GenBank accession No. AC_000159.1) to detect SNPs by PCR-restriction fragment length polymorphism (RFLP) methods. Primers, restriction enzymes selected (MBI Fermentas, St. Leon-Rot, Germany), and fragment sizes are given in Table 1.

For analysis of mutation locations in STAT4, the genomic sequence of the STAT4 gene (AC_000159.1) and the mRNA sequence (NW_003103844.1) were used to identify the exons of STAT4 through Spidey, an mRNA-to-genomic alignment program of the National Center for Biotechnology Information (NCBI; http://www.ncbi.nlm.nih.gov/IEB/Research/Ostell/Spidey).

PCR was carried out in a $25-\mu \mathrm{L}$ volume containing approximately $2.5 \mu \mathrm{L} 10 \mathrm{X}$ PCR buffer $\left(\mathrm{Mg}^{2+}\right), 200 \mu \mathrm{M}$ of each dNTP, $10 \mathrm{pM}$ of each primer, 2 U TransTaq HiFi DNA polymerase (Transgene, Beijing, China), and 50 ng Chinese Holstein cow genomic DNA as a template. Amplification conditions were as follows: initial denaturation at $94^{\circ} \mathrm{C}$ for $3 \mathrm{~min}$ followed by 35 cycles of denaturation at $94^{\circ} \mathrm{C}$ for $30 \mathrm{~s}$, annealing at $61^{\circ} \mathrm{C}$ for $30 \mathrm{~s}$, extension at $72^{\circ} \mathrm{C}$ for $30 \mathrm{~s}$ with extension at $72^{\circ} \mathrm{C}$ for $10 \mathrm{~min}$, and then holding at $4^{\circ} \mathrm{C}$ on a Mastercycler 5333 (Eppendorf AG, Hamburg, Germany).

Aliquots of $20-\mu \mathrm{L}$ PCR products of STAT4 were digested with $10 \mathrm{U}$ SduI (MBI Fermentas) for $4 \mathrm{~h}$ at $37^{\circ} \mathrm{C}$ following manufacturer instructions. The digested products were detected by electrophoresis on $2 \%$ agarose gel stained with ethidium bromide. Finally, 15 PCR products, 5 representatives for 3 electrophoresis patterns, were purified for sequencing in both directions. All DNA variants were located by Mutation Surveyor ${ }^{\mathrm{TM}}$ v4.0.4 (SoftGenetics, LLC, State College, PA).

\section{Statistical analysis}

Gene frequencies were determined for each locus by direct counting. Allele frequencies and polymorphism information content (PIC) were derived using the population genetic analysis package POPGENE, version 1.31 (Molecular Biology and Biotechnology Centre, 
University of Alberta, Edmonton, Canada) (Krawczak et al., 2006). Analyses of haplotype and linkage disequilibrium (LD) blocks were performed using HaploView, version 4.2 (Whitehead Institute for Biomedical Research, Cambridge, MA, USA). The haplotype block definition was followed according to that of Gabriel et al. (2002). They defined pairs to be in "strong LD" if the 1-sided upper $95 \%$ confidence bound of $\mathrm{D}^{\prime}$ is $>0.98$ (that is, consistent with no historical recombination) and the lower bound is above 0.7 .

The haplotype block was tested for deviations from Hardy-Weinberg equilibrium by means of a standard chi-squared test. The additive effect of SNPs was estimated as the difference between the mean of the 2 homozygotes divided by 2 , and dominance was estimated as the deviation of the heterozygote from the mean of the 2 homozygotes (Falconer and Mackay, 1996).

The relationship between the different haplotypes and milk performance traits was evaluated using a single-marker-lined model association analysis. Data were analyzed by fitting a general linear model using the restricted maximum likelihood method in the Statistical Package for the Social Sciences (SPSS; version 13.0; SPSS Inc., Chicago, IL, USA). The statistical analysis model included the fixed effects of haplotype and milk performance traits. The following 2 fixed-effect models were employed for analysis of milk performance traits in the Chinese Holstein cow, and least squares means were used for multiple comparisons of milk performance traits among different genotypes. The general model used for milk performance traits was as Equations 1 and 2:

$$
\begin{array}{cc}
\mathrm{Yij}=\mu \mathrm{i}+\mathrm{Mj}+\mathrm{eij} & \text { (Equation 1) } \\
\mathrm{Yijk}=\mu \mathrm{i}+\mathrm{Aj}+\mathrm{Dk}+\text { eijk } & \text { (Equation 2) }
\end{array}
$$

where Yij or Yijk is the phenotypic value of milk performance traits observed; $\mu i$ is the least square mean; $M j$ is the fixed effect of the $\mathrm{j}^{\text {th }}$ genotype ( 3 levels); $A j$ is the fixed effect of the $\mathrm{j}^{\text {th }}$ additive effect ( 3 levels); $D k$ is the fixed effect of the $\mathrm{k}^{\text {th }}$ dominant effect (2 levels); eij or eijk is the random residual effect of each observation. $A j=-0.5,0$, or 0.5 if individual $j$ had genotype $\mathrm{AA}, \mathrm{AB}$, or $\mathrm{BB}$, respectively, and $D k=1$ (or -0.5 ) if individual $i$ had genotype $\mathrm{AB}$ (or others).

\section{RESULTS}

\section{PCR-RFLP analysis and genetic polymorphism of the Chinese Holstein cow STAT4 gene}

To detect polymorphisms of Chinese Holstein cow STAT4, one primer pair (Table 1) was designed from the bovine STAT4 sequence (GenBank accession No. AC_000159.1 and NW_003103844.1) for PCR-RFLP analysis. Three PCR-RFLP patterns of STAT4 were observed and are shown in Figure 1. PCR products of different genotypes were sequenced and the sequences were analyzed with Mutation Surveyor ${ }^{\mathrm{TM}}$ (SoftGenetics). Results showed that 2 novel polymorphisms, a $\mathrm{G} \rightarrow \mathrm{A}$ mutation located at 95879 (the first nucleotide of AC_000159. is defined as 1) and a $\mathrm{G} \rightarrow \mathrm{C}$ mutation located at 96013, were apparent in the Chinese Holstein cow STAT4 gene (Table 2). Based on the Spidey analysis of bovine STAT4 sequences (AC_000159.1 and XM_002685461), both mutations were located in intron 20 of the STAT4 gene. Moreover, the mutation $\mathrm{G} \rightarrow \mathrm{C}$ at position 96013 formed an $S d u$ I endonuclease restriction site. A 375-bp PCR product digestion with $S d u$ I endonuclease produced different banding patterns, which were defined as GGGG, GAGC, and AACC genotypes. 
Table 1. PCR and PCR-RFLP tests used for genotyping single nucleotide polymorphisms detected in the bovine STAT4 gene.

\begin{tabular}{|c|c|c|c|c|c|c|}
\hline No. & Position & Primer sequences & Size (bp) & Restriction enzyme & RE size (bp/allele) & $\operatorname{Tm}\left({ }^{\circ} \mathrm{C}\right)$ \\
\hline 1 & $\begin{array}{l}\text { intron } 20 \\
\text { (according to the } \\
\text { Spidey analysis of } \\
\text { AC_000159.1 and } \\
\text { XM_002685461) }\end{array}$ & $\begin{array}{l}\text { F: 5'-CAGTAGCTAGACTTCCCCATG-3' } \\
\text { R: 5'- TGTCCAGGTATCGTTTTCAGC-3' }\end{array}$ & 375 & $S d u \mathrm{I}$ & $108(267 / g .96013 \mathrm{C})$ & 61 \\
\hline
\end{tabular}

$\mathrm{RE}=$ restriction enzyme; $\mathrm{Tm}=$ melting temperature.

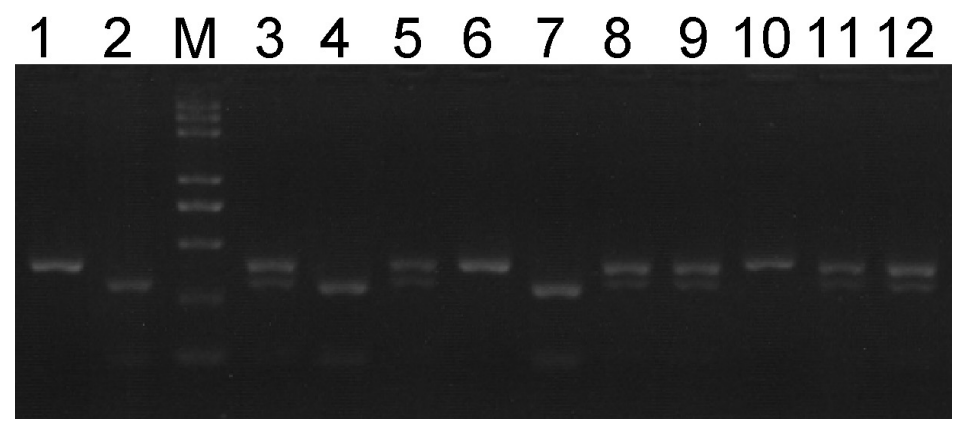

Figure 1. Representative restriction pattern observed for the 375-bp STAT4 gene intron 20 fragment of Chinese Holstein cow on 2\% agarose gel. Lane 1 = haplotype GGGG: 375 -bp fragment; lane 2 = haplotype AACC: 108- and 267-bp fragments; lane $M=$ molecular size marker (DL2000 plus); lanes 3, 5, 8, 9, 11, 12 = haplotype GAGC; lanes 6, $10=$ haplotype GGGG; lanes 4, $7=$ haplotype AACC.

Table 2. Sequence comparison among different genotypes.

\begin{tabular}{llcc}
\hline Genotypes & Nucleotide sequence & Location of mutation & Change of nucleotide \\
\hline AA & $\begin{array}{l}\text { gaaagaagaagtaatGattagaaagctgtta; } \\
\text { ctttgccagggagggGacaagggggttta } \\
\text { gaaagaagaagtaatAattagaaagctgtta; } \\
\text { ctttgccagggagggCacaagggggtctta }\end{array}$ & 95879 & $\mathrm{G} \rightarrow \mathrm{A}$ \\
$\mathrm{BB}$ & 96013 & $\mathrm{G} \rightarrow \mathrm{C}$ \\
\hline
\end{tabular}

Capital letters in bold represent mutations in the sequence.

\section{Intra-STAT4 LD}

To understand the intra-STAT4 LD of the 2 SNPs, D', $\mathrm{r}^{2}$, and log odds scores were estimated for each pair of SNPs in HaploView. Results are shown in Figure 2, where the red diamond indicates strong LD between 2 SNPs $\left(\mathrm{D}^{\prime}>0.8\right)$ with statistical significance [log odds score $>2.0$ (Barrett et al., 2005)]. The $\mathrm{r}^{2}$ value between the g.95879G $>\mathrm{A}$ and g.96013G $>\mathrm{C}$ in the haplotype block was 1, which showed that the 2 SNPs were completely linked with one another.

\section{Genetic polymorphism of the Chinese Holstein cow STAT4 gene}

Allele frequencies, genotype frequencies, and PIC of the haplotype block are presented in Table 3. Allele $\mathrm{G}$ at the locus 95879 and allele $\mathrm{G}$ at the locus 96013 were the predominant 
alleles. The results of PIC of the haplotype block indicated that the 2 SNPs should be considered as moderate polymorphisms (Table 3). Moreover, the genotype frequencies of STAT4 in Chinese Holsteins were not in accordance with Hardy-Weinberg equilibrium $(\mathrm{P}<0.01)$.

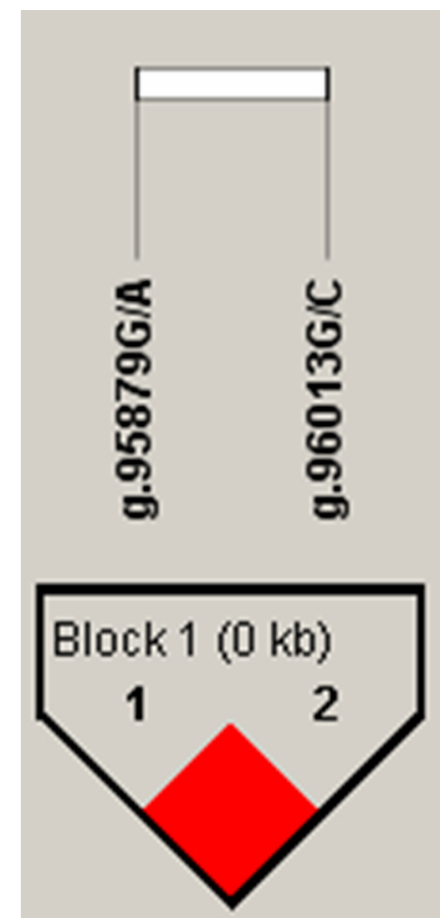

Figure 2. Linkage disequilibrium pattern among 2 single nucleotide polymorphisms at the STAT4 gene intron 20 by Haploview analysis.

Table 3. Frequencies of genotypes and alleles of the Chinese Holstein cow STAT4 gene.

\begin{tabular}{llcccc}
\hline Polymorphism & Genotypes & Genotypic frequencies & Alleles & Allelic frequencies & PIC \\
\hline g.95879G $>$ A & GGGG (129) & 0.2205 & GG & 0.5513 & 0.3724 \\
g.96013G $>$ C & GAGC (387) & 0.6615 & & & \\
& AACC (69) & 0.1180 & AC & 0.4487 & \\
\hline
\end{tabular}

$\mathrm{PIC}=$ polymorphism information content.

\section{Least-squares means and standard errors for milk performance traits of the $S d u I$ polymorphism of Chinese Holstein cow STAT4}

The least-squares means and standard errors for milk performance traits of the $S d u \mathrm{I}$ polymorphism of the Chinese Holstein cow STAT4 gene were calculated with a general linear model (Table 4). Significant statistical relationships were found between milk performance traits and different genotypes $(\mathrm{P}<0.05$; Table 4$)$. Cows with the GGGG haplotype showed 
higher milk yield at 305 days $(8055 \pm 105 \mathrm{~kg})$ in comparison to the cows with the AACC $(7897 \pm 165 \mathrm{~kg})$ or GAGC $(7700 \pm 74 \mathrm{~kg})$ haplotypes $(\mathrm{P}<0.05$; Table 4$)$, and lower protein percentage $(2.941 \pm 0.022)$ in comparison to the cow with the AACC $(3.042 \pm 0.034)$ or GAGC $(2.945 \pm 0.015)$ haplotypes $(\mathrm{P}<0.05$; Table 4$)$; however, the fat percentage among the 3 haplotypes showed no significant difference $(\mathrm{P}>0.05)$. These results indicate that cows with the GGGG haplotype had a tendency to achieve greater milk yield at 305 days and to lose a greater protein percentage than cows with AACC or GAGC haplotypes. In other words, 95879G and 96013G were the beneficial alleles for milk yield at 305 days, and 95879A and $96013 \mathrm{C}$ were the beneficial alleles for protein percentage.

Table 4. Milk performance traits of different STAT4 genotypes in Chinese Holstein cows.

\begin{tabular}{|c|c|c|c|c|c|c|c|}
\hline & \multirow{2}{*}{$\begin{array}{l}\text { SNP } \\
\text { g. } 95879 \mathrm{G}>A \\
\text { g. } 96013 \mathrm{G}>\mathrm{C}\end{array}$} & \multicolumn{3}{|c|}{ Genotype means $\pm \mathrm{SE}$} & \multirow{2}{*}{$\begin{array}{l}\text { Overall } \\
\text { P value }\end{array}$} & \multirow{2}{*}{$\begin{array}{c}\text { Additive } \\
\text { effect } \pm \text { SE }\end{array}$} & \multirow{2}{*}{$\begin{array}{l}\text { Dominant } \\
\text { effect } \pm \text { SE }\end{array}$} \\
\hline & & GGGG & GAGC & AACC & & & \\
\hline Milk yield at 305 days $(\mathrm{kg})$ & & $8055 \pm 105$ & $7700 \pm 74$ & $7897 \pm 165$ & 0.020 & $64 \pm 102$ & $-40 \pm 128$ \\
\hline Fat percentage $(\%)$ & & $4.123 \pm 0.074$ & $4.229 \pm 0.052$ & $4.228 \pm 0.117$ & 0.488 & $-0.053 \pm 0.069$ & $0.054 \pm 0.087$ \\
\hline Protein percentage $(\%)$ & & $2.941 \pm 0.022$ & $2.945 \pm 0.015$ & $3.042 \pm 0.034$ & 0.028 & $-0.050 \pm 0.020^{*}$ & $-0.046 \pm 0.020$ \\
\hline
\end{tabular}

$\mathrm{P}$ value for the overall genotype effect; additive effect is estimated as the difference between the 2 homozygous means divided by 2; dominant effect is estimated as the non-additive genetic effects or the deviation of the heterozygote from the mean of the 2 homozygotes. ${ }^{*} \mathrm{P}<0.01$ and $* \mathrm{P}<0.05$

Based on the definition presented by Falconer and Mackay (1996), the genetic effects of different $S d u$ I polymorphism genotypes analyzed by a general linear model in Equation 2 are summarized in Table 4. The results indicate a significant additive effect of $S d u$ I polymorphism genotypes on milk protein percentage but not on milk yield at 305 days or on milk protein percentage. Compared with genotypes g.95879GA/g.96013GC or g.95879AA/ g.96013CC, genotype g.95879GG/g.96013GG was associated with increased milk yield at 305 days and decreased milk protein percentage (Table 4). The additive and dominant effects of the STAT4 SduI polymorphism at intron 20 for milk yield at 305 days $(\mathrm{kg})$, fat percentage, and protein percentage are presented in Table 4. The 2 SNPs in STAT4 intron 20 had opposite dominant effects on milk yield and milk fat percentage. Furthermore, the dominant gene effect on milk yield at 305 days and on milk protein percentage was negative, which indicated negative heterosis. The homozygous wild-type alleles, $95879 \mathrm{G}$ and $96013 \mathrm{G}$, were significantly associated with the decrease in protein percentage. The absolute values of the additive effect on milk yield at 305 days and on protein percentage were higher than those of the dominant effect. These results indicate that the genetic locus characteristics agreed with the additivedominant model, and the additive gene effect played a more important role than the dominant gene effect.

\section{DISCUSSION}

As a member of the STAT family of molecules, STAT4 is seen as an important player that transduces interleukin-12 and -23, and type I interferon cytokine signals in T cells and monocytes, leading to T-helper type 1 and type 17 differentiation, monocyte activation, and production of interferon- $\gamma$ (Watford et al., 2004; Korman et al., 2008). A common haplotype 
of the human STAT4 gene was reported to be associated with susceptibility to rheumatoid arthritis, systemic lupus erythematosus, and primary Sjögren's syndrome (Korman et al., 2008; Su et al., 2010). Zhang et al. (2010) identified 4 SNPs from the Chinese Holstein cow STAT4, and found that the SNP (g.60330A $>$ G) markedly affected the 305-day matured equivalency $(\mathrm{P}<0.05)$ and fat content $(\mathrm{P}<0.05)$, which indicates the association between STAT4 and milk production traits in cattle. In the present study, using PCR-RFLP and DNA sequencing, we characterized intron 20 mutations of the STAT4 gene in Chinese Holstein cow and showed that the mutations were associated with milk production traits, which is the first report on STAT4 mutations identified from intron 20.

STAT4 is a mediator of type 1 cytokine signaling, and recognized as an important player in mammary glands (Watson and Neoh, 2008). The results reported here and in a paper by Zhang et al. (2010) revealed that mutations of STAT4 were associated with milk performance traits of Chinese Holstein cows, which provides further evidence supporting that STAT4 plays important roles in adult mammary development. However, the exact mechanism of SNPs in STAT4 that result in alterations of its function and lead to changes in milk performance traits in animals remains unknown.

Understanding the phenotypic influences caused by intronic SNPs is still a challenge at present. Many SNPs in introns are thought to be non-functional (Crawford et al., 2005; Buchanan et al., 2012). Meanwhile, increasing research is revealing that polymorphisms located in introns could influence gene expression by altering splice sites, disrupting a transcription factor-binding site, or a binding site for modified histone proteins (Aklillu et al., 2003; von Ahsen and Oellerich, 2004; Skarratt et al., 2005; Warnecke et al., 2005; Bu et al., 2006; Szafranski et al., 2007; Wang et al., 2011). It is unclear how intronic SNPs in STAT4 cause differences in milk performance traits in Chinese Holstein cows; however, it is possible that they have the potential to influence STAT4 expression or protein activity, and further studies are needed for this mechanism to be uncovered and well understood.

It is also quite possible that there are more milk performance-associated SNPs in introns or exons of STAT4. Identifying more functional variants that influence phenotypes can immensely contribute toward a better understanding of the associations between genotypic, cellular, and organismal phenotypes. In order to clarify the comprehensive function of STAT4 in adult mammary development, future studies should focus on identifying other SNPs at the whole STAT4 gene level and examining their contribution to milk production traits.

\section{ACKNOWLEDGMENTS}

Research supported by the Key Scientific \& Technological Project of the Zhejiang Province (\#2008C02002-1 and \#2010C12007), the National Natural Science Foundation of China (\#31001020), and the Scientific and Technological Innovation Team of Zhejiang Province (\#2010R50027).

\section{REFERENCES}

Aklillu E, Carrillo JA, Makonnen E, Hellman K, et al. (2003). Genetic polymorphism of CYP1A2 in Ethiopians affecting induction and expression: characterization of novel haplotypes with single-nucleotide polymorphisms in intron 1. Mol. Pharmacol. 64: 659-669.

Barrett JC, Fry B, Maller J and Daly MJ (2005). Haploview: analysis and visualization of LD and haplotype maps. 
Bioinformatics 21: 263-265.

Brym P, Kaminski S and Rusc A (2004). New SSCP polymorphism within bovine STAT5A gene and its associations with milk performance traits in Black-and-White and Jersey cattle. J. Appl. Genet. 45: 445-452.

$\mathrm{Bu}$ D, Tomlinson G, Lewis CM, Zhang C, et al. (2006). An intronic polymorphism associated with increased XRCC1 expression, reduced apoptosis and familial breast cancer. Breast Cancer Res. Treat. 99: 257-265.

Buchanan CC, Torstenson ES, Bush WS and Ritchie MD (2012). A comparison of cataloged variation between International HapMap Consortium and 1000 Genomes Project data. J. Am. Med. Inform. Assoc. 19: 289-294.

Burdon TG, Maitland KA, Clark AJ, Wallace R, et al. (1994). Regulation of the sheep beta-lactoglobulin gene by lactogenic hormones is mediated by a transcription factor that binds an interferon-gamma activation site-related element. Mol. Endocrinol. 8: 1528-1536.

Crawford DC, Akey DT and Nickerson DA (2005). The patterns of natural variation in human genes. Annu. Rev. Genomics Hum. Genet. 6: 287-312.

Dario C and Selvaggi M (2011). Study on the STAT5A/AvaI polymorphism in Jersey cows and association with milk production traits. Mol. Biol. Rep. 38: 5387-5392.

Darnell JE Jr (1997). STATs and gene regulation. Science 277: 1630-1635.

Falconer DS and Mackay TFC (1996). Introduction to Quantitative Genetics. 4th edn. Longman Scientific and Technical, New York.

Flisikowski K, Szymanowska M and Zwierzchowski L (2003). The DNA-binding capacity of genetic variants of the bovine STAT5A transcription factor. Cell Mol. Biol. Lett. 8: 831-840.

Gabriel SB, Schaffner SF, Nguyen H, Moore JM, et al. (2002). The structure of haplotype blocks in the human genome. Science 296: 2225-2229.

Gouilleux F, Wakao H, Mundt M and Groner B (1994). Prolactin induces phosphorylation of Tyr694 of Stat5 (MGF), a prerequisite for DNA binding and induction of transcription. EMBO J. 13: 4361-4369.

He X, Chu MX, Qiao L, He JN, et al. (2012). Polymorphisms of STAT5A gene and their association with milk production traits in Holstein cows. Mol. Biol. Rep. 39: 2901-2907.

Horvath CM (2000). STAT proteins and transcriptional responses to extracellular signals. Trends Biochem. Sci. 25: 496502.

Khaled WT, Read EK, Nicholson SE, Baxter FO, et al. (2007). The IL-4/IL-13/Stat6 signalling pathway promotes luminal mammary epithelial cell development. Development 134: 2739-2750.

Khatib H, Monson RL, Schutzkus V, Kohl DM, et al. (2008). Mutations in the STAT5A gene are associated with embryonic survival and milk composition in cattle. J. Dairy Sci. 91: 784-793.

Korman BD, Kastner DL, Gregersen PK and Remmers EF (2008). STAT4: genetics, mechanisms, and implications for autoimmunity. Curr. Allergy Asthma Rep. 8: 398-403.

Krawczak M, Nikolaus S, von Eberstein H, Croucher PJ, et al. (2006). PopGen: population-based recruitment of patients and controls for the analysis of complex genotype-phenotype relationships. Community Genet. 9: 55-61.

Levy DE and Darnell JE, Jr. (2002). Stats: transcriptional control and biological impact. Nat. Rev. Mol. Cell Biol. 3: 651662.

Schmitt-Ney M, Happ B, Hofer P, Hynes NE, et al. (1992). Mammary gland-specific nuclear factor activity is positively regulated by lactogenic hormones and negatively by milk stasis. Mol. Endocrinol. 6: 1988-1997.

Selvaggi M, Dario C, Normanno G, Celano GV, et al. (2009). Genetic polymorphism of STAT5A protein: relationships with production traits and milk composition in Italian Brown cattle. J. Dairy Res. 76: 441-445.

Sims SH, Cha Y, Romine MF, Gao PQ, et al. (1993). A novel interferon-inducible domain: structural and functional analysis of the human interferon regulatory factor 1 gene promoter. Mol. Cell Biol. 13: 690-702.

Skarratt KK, Fuller SJ, Sluyter R, Dao-Ung LP, et al. (2005). A 5' intronic splice site polymorphism leads to a null allele of the $\mathrm{P} 2 \mathrm{X} 7$ gene in 1-2\% of the Caucasian population. FEBS Lett. 579: 2675-2678.

Su Y, Zhao Y, Liu X, Guo JP, et al. (2010). Variation in STAT4 is associated with systemic lupus erythematosus in Chinese Northern Han population. Chin. Med. J. 123: 3173-3177.

Szafranski K, Schindler S, Taudien S, Hiller M, et al. (2007). Violating the splicing rules: TG dinucleotides function as alternative 3' splice sites in U2-dependent introns. Genome Biol. 8: R154.

von Ahsen N and Oellerich M (2004). The intronic prothrombin 19911A $>$ G polymorphism influences splicing efficiency and modulates effects of the $20210 \mathrm{G}>\mathrm{A}$ polymorphism on mRNA amount and expression in a stable reporter gene assay system. Blood 103: 586-593.

Wakao H, Gouilleux F and Groner B (1995). Mammary gland factor (MGF) is a novel member of the cytokine regulated transcription factor gene family and confers the prolactin response. EMBO J. 14: 854-855.

Wang D, Guo Y, Wrighton SA, Cooke GE, et al. (2011). Intronic polymorphism in CYP3A4 affects hepatic expression and response to statin drugs. Pharmacogenomics J. 11: 274-286. 
Warnecke C, Mugrauer P, Surder D, Erdmann J, et al. (2005). Intronic ANG II type 2 receptor gene polymorphism 1675 G/A modulates receptor protein expression but not mRNA splicing. Am. J. Physiol. Regul. Integr. Comp Physiol. 289: R1729-R1735.

Watford WT, Hissong BD, Bream JH, Kanno Y, et al. (2004). Signaling by IL-12 and IL-23 and the immunoregulatory roles of STAT4. Immunol. Rev. 202: 139-156.

Watson CJ and Neoh K (2008). The Stat family of transcription factors have diverse roles in mammary gland development. Semin. Cell Dev. Biol. 19: 401-406.

Yamaji D, Na R, Feuermann Y, Pechhold S, et al. (2009). Development of mammary luminal progenitor cells is controlled by the transcription factor STAT5A. Genes Dev. 23: 2382-2387.

Zhang F, Huang J, Li Q, Ju Z, et al. (2010). Novel single nucleotide polymorphisms (SNPs) of the bovine STAT4 gene and their associations with production traits in Chinese Holstein cattle. Afr. J. Biotechnol. 9: 4003-4008.

Zhong Z, Wen Z and Darnell JE Jr (1994). Stat3 and Stat4: members of the family of signal transducers and activators of transcription. Proc. Natl. Acad. Sci. U. S. A. 91: 4806-4810. 